\title{
Intergenerational perception of the utility of major transport projects
}

\author{
Domingo Penyalver ${ }^{a}{ }^{*}$, Mateu Turró ${ }^{b}$, Diana Zavala-Rojas ${ }^{c}$ \\ a International Center for Numerical Methods in Engineering, Polytechnic University of Catalonia, 08034 Barcelona, Spain \\ b Department of Transport and Regional Planning, Polytechnic University of Catalonia, C. Jordi Girona, 1-3 Edif. C3-S120, 08034 Barcelona, Spain \\ ${ }^{\mathrm{c}}$ Faculty of Political and Social Sciences, Universitat Pompeu Fabra, C. Ramon Trias Fargas, 25-27, 08005 Barcelona, Spain
}

\section{A R T I C L E I N F O}

\section{Article history:}

Received 24 February 2017

Received in revised form

12 November 2017

Accepted 13 November 2017

Available online $\mathrm{xxx}$

\section{JEL classification:}

R42

R48

$\mathrm{Z} 13$

Z18

Keywords:

Intergenerational analysis

Equity analysis

Redistributive effects

Intergenerational Redistributive Effects

Model

IREM

Intergenerational fairness

Project financing

Redistribution

Cost Benefit Analysis

Transport infrastructure

\begin{abstract}
A B S T R A C T
A basic question for the assessment of the fairness of a project financing formula on successive generations is to determine what is the most appropriate method to group the affected individuals over the years. The generational approach in the "Intergenerational Redistributive Effects Model" (IREM) deals with it through the ad-hoc concept of overlapping annual generations. This concept requires establishing the number of years (or timespan) included in the generation and how to incorporate in it those individuals living in years that are not the central one. To do so in a way that reflects the sensitivity of society to the effects of a major transport infrastructure project, specific surveys with a novel approach were designed. The outputs from the survey carried out in Catalonia show evidence suggesting that discount functions should tend to decline at a higher rate in the short term than in the long term. Thus, future impacts of transport investments, both future socio-economic net benefits and financial burdens, should be considered less important than immediate (present) outcomes in the decision-making process. Further, there are reasons to consider that discounting is not neutral to reflect the social interest of large-scale transport projects for the successive generations involved.
\end{abstract}

(c) 2017 Elsevier Ltd. All rights reserved.

\section{Introduction}

Understanding how people perceive, evaluate and undergo the effects of major investments should be particularly relevant for decision makers. To a large extent, people's preferences and their support to investment decisions depend, among other factors, on their experiences and expectations on the positive and negative outcomes that may result from investments with capacity to constraint individuals' future choices (Lewis, 2001; McLachlan \& Gardner, 2004). For example, when dealing with major investments enhancing mobility in congested areas, the well-known benefits (travel time savings, environmental positive impacts from

\footnotetext{
* Corresponding author.

E-mail addresses:_dopeyro@gmail.com,_domingo.penalver@upc.edu (D. Penyalver), m.turro@upc.edu (M. Turró), diana.zavala@upf.edu (D. Zavala-Rojas).
}

reduction in pollution, etc.) that are immediately perceived are frequently more important for individuals that the costs and benefits that are uncertain, delayed or that might occur to others elsewhere (Gatting \& Hendricks, 2007).

The financial structuring of the investments that the society "of each moment" requires is also of great importance. At the macroeconomic level, disposing of money to pay for the construction of an infrastructure project will affect public accounts and divert funds from other potential uses. At the microeconomic level, the financial structure determines who will end up paying for the investment. As this structure typically adjourns actual payments through credit facilities, it affects future cash flows and, as a consequence, it has intergenerational impacts. These impacts can be assessed through a model that compares the allocation of net socioeconomic benefits over time with the flows of obligations (in terms of payments) arising from the financing formula. The effects 
that are identified using the Intergenerational Redistributive Effects Model or IREM (Penyalver \& Turró, 2017) may have strong impacts on the social welfare of generations to come and should thus be considered in the decision-making process.

The paper explains the process followed to identify the perception of the citizens on the effects on the welfare of their generation and on future ones of major investments in infrastructure. This perception is essential for the definition of the concept of "annual generation", which is critical for the IREM. The paper explains the issues that led to the development of IREM and the use of a specific survey to determine some key parameters of the model. Surveys are essential for gathering data in the applied social sciences (Groves, Mosher, Lepkowski, \& Kirgis, 2009). In this case it was necessary to place the respondent in a forthcoming situation to obtain her appreciation of the impact of major transport infrastructure projects on someone living in the future. The work represents a first step into the incorporation, with a degree of objectivity, of the redistribution effects of such infrastructure projects on the multiple generations affected.

\section{The intergenerational effects of major projects}

The decision-making process for major infrastructure projects focuses on selecting those that represent the best use of resources for society. Feasibility studies are expected to estimate the socioeconomic profitability of a project, which is the key indicator of its efficiency. This profitability is calculated using classical economic models, ${ }^{1}$ which assume that a single theoretical welfarefunction can adequately represent the preferences of the different (overlapped) generations bearing the costs and the benefits of an investment. The balance between these costs and benefits is referred to the moment of the analysis through discounting. Properly applied, discounting is useful to establish how much future benefits and costs are worth today (static perspective). In essence, the future utility of an infrastructure investment is assumed to be the additional social welfare generated during the project lifecycle, measured through the economic net present value (ENPV).

A critical point in the discussion about the assessment of the long-term effects of certain investments in civil infrastructure projects, such as nuclear plants, which have obvious impacts on future generations, is whether the method of discounting and/or the value of the social discount rate in Cost Benefit Analysis (CBA) lead to the right conclusions in terms of efficiency for all the people affected over the project life. Discounting methods of long-term effects are problematic because some people's values and preferences are treated differently because they live at different times (Lee \& Ellingwood, 2015). In the discussions on discounting the concept of intergenerational redistributive effects is, nonetheless, absent in spite of the clear differential impacts across generations of certain long-run effects (e.g. climate change) of major investments with long timespans $(50,100$ or more years).

Properly placing the project effects over time is essential for ENPV calculations. This requires estimating the preferences of the affected individuals. Preferences may be analysed with standard methods when framed in relatively short-term time horizons and within an intragenerational context. Integrated investment programmes and major infrastructure projects must be

\footnotetext{
${ }^{1}$ Cost-Benefit Analysis (CBA) is the microeconomic model traditionally used to measure efficiency for major infrastructure projects. The main outcome from CBA is the Economic Net Present Value (ENPV), which is limited to the costs and benefits that can be monetised and entails using a suitable social discount rate (SDR).
}

placed, however, in an intergenerational context, which addresses extremely long-term horizons and the impacts on and preferences of unborn generations (EPA, 2016). The distinction between both contexts is important to establish whether the method of discounting is suitable to adequately represent the impacts of major projects and, if so, which social rate of time preference should be used in each case (Groom, Hepburn, Koundouri, \& Pearce, 2005). The conflicts between intragenerational and intergenerational effects are often set up under the perspective of the sustainable use of natural resources. It can be argued, though, that the redistribution effects across generations should go beyond this and also consider a fair split of economic and financial impacts.

The consideration of intergenerational effects on decision making -in principle through a kind of multicriteria analysis- is more justified when dealing with major infrastructure investments, ${ }^{2}$ as they mobilise huge amounts of economic resources, are prone to complex financial structures, including public-private partnerships (PPPs), and have very long project cycles. In this type of investments, the government promoting the investment (GPI) may use a wide range of management systems and funding options to develop the project. ${ }^{3}$ These options will determine the relationship between the net socioeconomic benefits during the operation of the project and the actual end-of-the-line payments for its construction. To help understanding the issue, it is worth to imagine a situation where the whole investment is financed by the GPI through a bullet loan. ${ }^{4}$ Those individuals belonging to the generations at the end of the loan cycle would end up bearing most of the financial costs, unless they are able to refinance the loan, ${ }^{5}$ whilst their net benefits in terms of resources would probably be even less than average due to congestion, poorer performance, etc., and very uncertain besides. The particular aspects of transport infrastructure investments are therefore most adequate to analyse intergenerational effects.

IREM has been specifically developed to analyse whether there exists a balanced distribution between the socioeconomic net benefits and the financial burden over time for the different overlapping generations concerned by the project. IREM's outputs should only be analysed, however, in terms of fairness/unfairness. ${ }^{6}$ Efficiency is, in principle, assessed from the CBA, using an adequate social discount rate (SDR). But overall efficiency does not take into account how the project is financed (as financial cash-flows are essentially transfers that are not affecting the Cost-Benefit Analysis or $C B A$, although they are often used to value resources). The intergenerational analysis is complementary to the CBA and provides a view of the fairness of the actual financial payments for the project across the various generations affected. This analysis requires both defining a "generation" and an ad-hoc utility function that reflects the economic preferences of this generation. This estimation process is the object of this paper.

\footnotetext{
2 The IREM model used in the research has been applied essentially to transport infrastructure projects.

3 The GPI may fund the investment directly through its annual budget or using bank loans (that will be repaid using budget funds), or may decide to delegate the management of the project to a public Agency or Company. The GPI may also decide developing the project by means of a public-private partnership, including a pure concession. A key issue is how users will pay for the use of the infrastructure.

${ }^{4}$ It is a loan where the repayment of the entire principal, sometimes even the principal and interest, is due at the end of the loan term.

${ }^{5}$ In any case the burden of refinancing will fall upon them.

6 The "fair/unfair" concept refers to moral obligations towards future generations (Rawls, 1972). We consider that human cooperation is possible and necessary for coexisting individuals on a specific territory, but also across territories and across individuals living in different time spans (generations).
} 


\section{Objectives of the research}

A main challenge in the elaboration of the IREM model was incorporating how citizens perceive their integration in a particular generation when it is concerned by an infrastructure project with a very long time projection and how citizens, placed within their own generation, apprehend the effects of such a project both in terms of its benefits and the predisposition to pay for them. Conventional surveys place the respondent in the present or in well-defined future contexts. In our case it was necessary both to place the respondent in a complex future situation and as part of a group of people who would be affected by the project over time. This required a new approach in the preparation of the questionnaire and in the quantification process. The cooperation between psychologists and project specialists (engineers, economists, financiers) was essential to prepare the questionnaires and to analyse the outcomes of the survey. The results of this research show the importance of a multi-disciplinary approach in developing tools for project appraisal.

This paper focuses on the work carried out to: 1) establish the most suitable timespan to properly represent a generation in the IREM, and 2) define a utility function that represents society's preferences within each generation according to the main features and effects of major infrastructure projects. After these introductory chapters, Section 4 reviews the main features of the utility functions characterising the collective preferences in the allocation of consumption across generations ${ }^{7}$ in the traditional economic approach. Section 5 contains a brief presentation of the generational concept used in the IREM model to assess the fairness of a project financing formula on successive generations. Section 6 presents the methodology followed for designing and conducting the survey carried out in Catalonia to estimate the parameters of the model in a real context and its main findings. Here, the parameters that define a generation linked to major transport projects are introduced. Finally, in Section 7, the main conclusions of the research are highlighted.

\section{Intertemporal choice models review}

The discounting mechanism and the SDR are critical in determining the social value of major investments in infrastructure. They both make up the function that in CBA transforms future costs and benefits into an ENPV for the generation in which the decision is taken. ENPV is a key indicator of the project's efficiency from the perspective of the overall society of the time of the decision to build. ${ }^{8}$ SDR, on the other hand, explains how decision makers perceive the propensity of present generations to renounce to immediate consumption in order to have the possibility to consume more in the future and thus an indication of how public resources are used to maximise the welfare of the citizens affected by the investment over its project cycle.

The theoretical framework of the SDR comes from the Ramsey Model (Ramsey, 1928). Social welfare can be conceptualised through a function $\left(W_{t}\right)$ representing its dynamic of change that, in turn, is represented by the intertemporal sum of the utility that a person obtains from individual consumption.

\footnotetext{
7 Traditional macroeconomic approach assumes implicitly that the generational concept has a genealogical meaning.

8 The time when the project is formally given the go-ahead (Flyvbjerg, 2005) When this date is not available or representative, the date of project approval by the main financiers can be adopted as the time of decision.
}

$\begin{array}{ll}\text { - } W_{t}=U\left(C_{t}\right) & \begin{array}{l}\text { Value of welfare on each " } t \text { " period in terms of utility } \\ \text { from individual consumption }\end{array} \\ \text { - } r=\log _{e}(1+i) ; & \begin{array}{l}\text { Continuously rate of discount/interest } \\ \text { (Samuelson, 1937) }\end{array} \\ \text { - } i & \text { Rate of discount/interest per unit of time }\end{array}$

Equation (1). Dynamic Social Welfare Function

$W=\int_{0}^{\infty} W_{t} \cdot e^{-r t} d t$

Graphically, it is possible to build up a preference function from the concept of indifference curve introduced by Irving Fisher (cf. Fig. 1). For a particular income level the indifference curve ' $U$,' represents the relationship between two amounts of different goods that entail the same satisfaction degree for consumers (Fisher, 1930). The more income the higher ability to obtain goods, and thus the curve moves from $U_{1}$ to $U_{2}, U_{3} \ldots$ For an investment, the question of interest is to determine how much consumption in the present will become consumption in a second period of time taking into account its expected utility.

The $\mathrm{X}$ axis represents the individuals' consumption in year 1 from the available annual budget. The Yaxis represents the amount saved for future consumption in year 2 . The line CG represents the consumer's possible use of the budget for year 1 . Its slope $m$ is frequently referred as the Consumption Rate of Interest (CRI); $C R I=-(m+1)$.

Curve $\mathrm{CH}$ shows the real opportunities of transforming present consumption into future consumption through investment. Its slope represents the social productivity of investment for society as a whole, which is expressed through the internal rate of return of the capital invested. The marginal efficiency of capital between two consecutive years decreases with the investment amount. Assuming $U\left(C_{t}\right)$ is time invariant, its first derivate is $U^{\prime}>0$ and $U^{\prime \prime} \leq 0$, and CRI is defined as the rate at which the marginal welfare of consumption falls over time:

Equation (2). Consumption Rate of Interest

$C R I=-\frac{\left(\frac{d W_{c t}}{d t}\right)}{W_{c t}}$

\footnotetext{
- $W_{c t} \quad$ Welfare effect of a marginal increase in the consumption in period $t$
}

A multitude of factors could have influence on the value of CRI. On the one hand, individuals may consider that the consumption satisfying present needs is more useful that the same consumption in a period afterwards (decreasing marginal utility of consumption), which can be explained by a question of impatience or immediacy (Harrod, 1948; Pigou, 1920; Ramsey, 1928) and certain aversion to the risk involved in postponing consumption (Arrow, 1970; Pratt, 1964). Some individuals could even take into account their own probability of death at the moment of making decisions about consumption/saving (Angelsen, 1991). In sum, although pure time preference is heterogeneous among the agents within an economy (Gollier \& Zeckhauser, 2003), the former arguments justify considering time consumption preferences at the moment of 


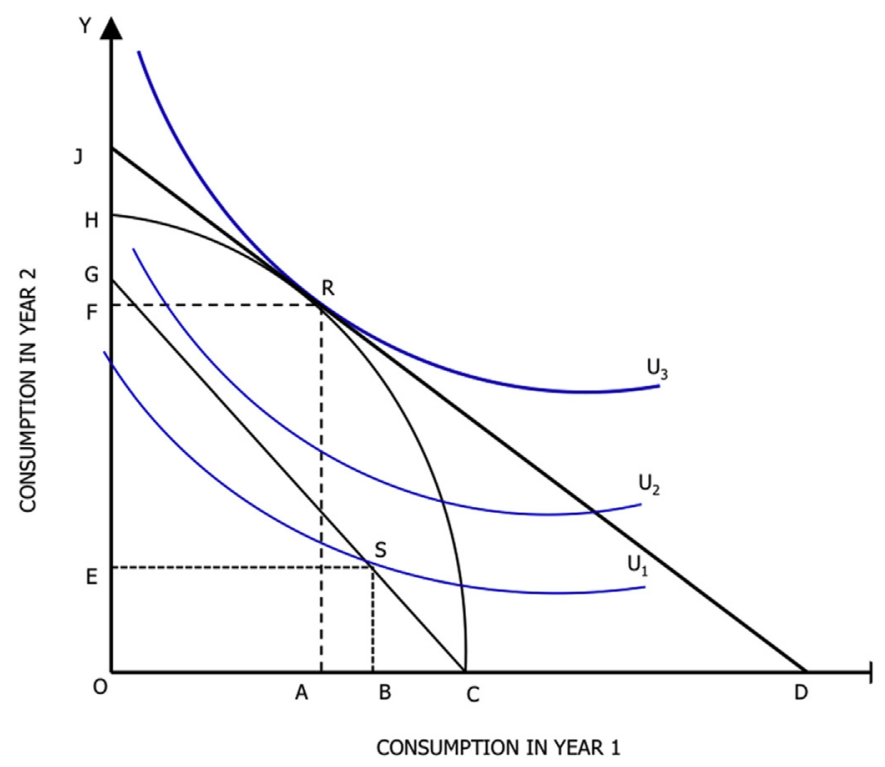

Fig. 1. Optimum inter-temporal choice scheme. Source: adaptation from Feldstein (1964).

establishing the value for SDR (Eckstein, 1961; Scott, 1977, 1989; Tinbergen, 1956).

According to the Ramsey Rule, SDR encompasses society's pureconsumption preferences (social value) and other factors related to the social productivity of collective investments for society (opportunity cost for society or social cost).

Equation (3). Ramsey Rule

$r=\rho+\theta g=\delta$

\footnotetext{
- $g$ Growth rate of consumption. As it is expected some economic growth over time, it is assumed that $g>0$.

- $\theta \quad$ Elasticity of inter-temporal substitution (marginal utility of consumption): it is a measure of the curvature of the utility function, and is mathematically equivalent to the coefficient of relative risk aversion; $\theta=-U$ " $/ U C_{t} . \theta>0$. High " $\theta$ " implies a strong preference for consumption now rather than in future periods. If $\theta=0$, the welfare increase of one monetary-unit extra income to the consumer is the same regardless of his initial consumption.

- $\rho \quad$ Rate of time preference of consumption; $\rho>0$ implies that individuals prefer early consumption to later consumption, even if the consumption level is the same.
}

Equation (3) shows the relationship between the social rate of time preference $(\delta)$, the "utility discount rate" or rate of pure time preference $(\rho)$, and the social rate of return to investment $(r)$, which matches with the private return to investment $(i)$ in absence of externalities and other distortions (Groom et al., 2005). Each of these rates is a contender for use as the SDR, where the appropriate discount rate for use in CBA depends upon the numeraire employed (Groom et al., 2005).

Combining factors $g$ and $\rho$ it is possible to obtain different values for SDR. As shown in Table 1, with positive growth and concave utility the SDR will be positive. In this case, discounting consumption streams in CBA can be synonymous with the equal treatment of generations' welfare (Lind, 1995).

Positive values for SDR do not imply $\rho>0$, which means that the individuals' pure time-preference might or not vary over time.
Table 1

Different cases for the function of discount rate.

\begin{tabular}{lll}
\hline & $\rho>0$ & $\rho=0$ \\
\hline$[1] \theta g>0$ & $C R I>0$ & $C R I>0$ \\
[2] $\theta g=0$ & $C R I>0$ & $C R I=0$ \\
[3] $\theta g<0$ & $?$ & $C R I<0$ \\
\hline
\end{tabular}

Source: adaptation from Angelsen (1991)

Actually, if the marginal utility rate of consumption ( $g$ ) is not regressive for individuals, the future effects will be less important than those at the moment of the analysis, independently of the consumer's time preferences. On the other hand, if $\rho>g$ or $\rho \sim 0$, individuals could prefer immediate consumption and have therefore lower propensity to save, which from a collective perspective can lead to postpone investments and to reduce the flow of benefits for future generations. This collective behaviour would imply a negative impact on future generations (Moellendorf, 2014; Olson \& Bailey, 1981). Finally, as $\theta$ represents preferences for smoothing consumption over time, high values of $\theta$ would be correlated to (comparatively) small ones for the marginal utility rate of consumption ( $g$ ) and vice versa (Dasgupta, 2007).

In conclusion, from a theoretical perspective, the SDR value should reflect both society's preference for present consumption rather than future one (social value approach) and the yield that could be obtained from the economic resources spent in a project in the best alternative investment (social cost approach). However, both values for the SDR could be quite different (Angelsen, 1991; Arrow \& Kurz, 1970; Arrow et al., 2004; Feldstein, 1964; Fernández-Baca, 2011; Gollier, 2011; Laibson, 1997; Moore et al., 2004; Roumboutsos, 2010; Souto, 2003).

In the first approach, the discounting method transforming future socio-economic costs and benefits into present values does not have to adopt necessarily a constant discount rate. In the social cost approach, the opportunity cost for society is associated to the private return to investment (i), reflecting the perception of the average member of society, which undoubtedly has a more or less conscious relation with the financial interest rates. In this approach, to estimate the SDR for CBA it is assumed that resources can be distributed through generations, through investments in infrastructure assets having maturities limited to 30-40 years being financed by mechanisms that meet the requirements of financial markets (Lee \& Ellingwood, 2015). But there are multiple funding sources of capital and a variety of financing instruments (bonds, loans, tailored facilities, etc.), different risk perceptions, a volatile money supply, etc. that imply, not only a broad range of interest rates for long-term assignment of money, but strong variations in these rates in the capital markets over the years. In any case, the rate of return for private capital is hardly representative of the social values that the SDR implies. Financial markets focus on maximising private benefits, keep a clear general risk aversion and show an opportunistic behaviour ${ }^{9}$ (von Hagen, Schuknecht, \& Wolswijk, 2011), and their expectations seem to have little correlation with society's willingness to delay consumption.

On the social value approach the estimation problems are also overwhelming, because it is practically impossible to estimate the return of the great number of opportunities foregone, which depend on the sector, investment amounts, etc. The solution adopted by most administrations is to take into consideration both aspects (social value and social cost) and adapt the rate of return to private capital, whatever the means to calculate it, through a

\footnotetext{
${ }^{9}$ It is obvious when observing bond yield spreads in the various EU countries during the financial crisis.
} 
“shadow value" (Feldstein, 1964).

Thus, it is not possible to speak of a single 'appropriate' discount rate but of an efficient discount rate ${ }^{10}$. This rate should (ideally) reflect both the social value and the social opportunity cost of project development but, in practice, the choice of the "appropriate" SDR for a given project or project sector has been defined by the public administrations in order to achieve certain policy objectives (Evans \& Sezer, 2004; Henderson \& Bateman, 1995; HM; Leleur, Salling, \& Jensen, 2007; Meunier, Quinet, \& Quinet, 2013; Treasury, 2003).

The decision on the SDR value to be used is critical in determining which projects will pass a CBA test. The potential influence of the SDR in long-term investments, with benefits and cost accruing over several generations, is particularly strong because even small changes in the discount rate have a significant impact on the indicators supporting decision-making (Lee \& Ellingwood, 2015). Following the rational choice theory, discounting methods usually employ an exponential discount function (Coleman \& Fararo, 1992; Frederick, Loewenstein, \& O'donoghue, 2002; Gollier, Koundouri, \& Pantelidis, 2008; Laibson, 1997). Under the usual SDRs, the costs and benefits accruing to generations in the distant future appear relatively unimportant in present values terms.

In formal discounting models it is assumed that consumer's welfare can be represented as a discounted sum of current and future utility (cf. Equation (4)). Thus, that utility can be referred to as consumption or income (Arrow \& Kurz, 1970; Arrow et al., 1995, pp. 128-144, 2014; Freeman, Groom, Panapoulou, \& Pantelidis, 2015; Gollier, 2011; Laibson, 1997; Samuelson, 1937). 2003)

Equation (4). Ramsey's generalised discounted model (Laibson,

$W \equiv U_{t}=\sum_{\tau=0}^{T-t} D(\tau) \cdot u_{t+\tau}$

\begin{tabular}{ll}
\hline$-U_{t}$ & Total utility from the perspective of the current period (year) " $t$ " \\
$-D(\tau)$ & $\begin{array}{l}\text { Adaptation to year } 0 \text { of the welfare of the consumer occurring at } \\
\text { time " } \tau \text { "; sometimes called objective utility function or "discount } \\
\text { function". The higher the discount rate }{ }^{11} \text { the greater the preference } \\
\text { for immediate benefits over delayed rewards. }\end{array}$ \\
- $\tau \equiv \Delta t$ & $\begin{array}{l}\text { Time period used to discount the utility series until the horizon year } \\
\text { at the frequency " } \Delta \text { ". }\end{array}$ \\
The last period considered (for example, the last year in the lifecycle \\
of an investment)
\end{tabular}

In Equation (4), the total utility $\left(U_{t}\right)$ is an additive function. The benefits obtained of immediate consumption have no effect on the utility of the benefits obtained afterwards. Otherwise, incongruence from time inconsistency results in consumption and saving

\footnotetext{
10 The efficient discount rate can be estimated in three different ways: as the continuously changing rate of interest from financial markets, as the marginal rate of return on productive capital in the economy, and as the welfare-preserving rate of return on savings (Gollier, 2011). The rate to be obtained from reinvestment of returns and the risk differences between private and public investments have also been considered determinants of the socially efficient discount rate (Baumol, 1968). Even if we were able to estimate these values, it seems evident that we cannot speak of a single appropriate discount rate (Stiglitz, 2013).

${ }^{11}$ It is not, however, the discount rate used by economists to discount future cash flows, although there is a link between both.
}

plans that are sub-optimal for all generations (Weitzman, 1998). Whilst it is assumed that the consumers' preferences do not change over time, granting the property of time consistency, discounting utility at a constant rate $(\rho)$ insures that the mechanisms that constitute the basis of decision-making are also time consistent -cf. Equation (5)-. This assumption known as time consistency or $d y$ namic consistency allows isolating time 0 and time $t$ in the welfarepreserving discount rate evaluation: in time $t=0$, preference reaches its maximum $D(0)=1$. For $t>0$, the discount function slopes down as time increases, $D^{\prime}(t) \leq 0$. Therefore, $1=D(0) \geq D(t) \geq D^{\prime}(t) \geq 0$, with $\rho(t)=-D^{\prime}(t) / D(t)$ being the rate at which the discount function declines.

Equation (5). General expression of the exponential discount function (Laibson, 2003)

$$
D(t)=\lim _{\Delta \rightarrow 0}\left(\frac{1}{1+\Delta \cdot \rho(t)}\right)^{1 / \Delta}=e^{-\rho(t)}=\delta^{t}
$$

A second body of research argues, however, that choice behaviour is largely inconsistent (Little, 2002). For some authors, discounting utility appears 'ethically indefensible', 'rapacious' and 'defective' from an intergenerational perspective, in spite that, under certain conditions (context), it can be useful to reflect how society's time preferences decline (Freeman \& Groom, 2014; Harrod, 1948; Ramsey, 1928). Since economists' conclusions about economic welfare incorporate consumers' behaviour in a timeless manner (Little, 2002), «decisions made today on the basis of CBA appear hence to tyrannise future generations and, by extension, discounting appears to be contrary to the widely supported goal of sustainability» (Arrow et al., 2013). This occurs because, on the one hand, time preferences vary due to uncertainty and to other contextual factors, such as price fluctuation of goods and services (Arrow et al., 2013, 2014; Coleman \& Fararo, 1992; Frederick et al., 2002; Freeman et al., 2015; Gollier et al., 2008; Groom et al., 2005) and, on the other hand, market prices do not exist for many of the determinants of utility such as environmental assets. In this sense, the theoretical framework for intertemporal choices modelling resembles the one used in business, which applies a compound interest formula, and does not adequately reflect the collective preferences over time (Frederick et al., 2002).

Research shows that individuals prefer a smaller but earlier reward than a larger reward coming later in time (Kirby \& Herrnstein, 1995). According to this, the SDR over longer time horizons should be lower than over shorter ones (Frederick et al., 2002), implying that costs and benefits should be discounted at higher rates in the short run than in the long run (Arrow et al., 2014; Frederick et al., 2002; Laibson, 2003; Soman et al., 2005).

A recently proposed solution to estimate discount rates for the very long-term, which is the case of investments encompassing very large timespans whose costs and benefits entail high degrees of uncertainty (e.g., high speed railway networks development, nuclear power, etc.), is to use a declining discount rate (DDR) according to some predetermined trajectory. There is no consensus, however, on how to apply this solution. On the one hand, declining utility discount rates may produce time inconsistent planning (Groom et al., 2005). Whilst dynamic inconsistency, i.e. violating the assumption of time consistency, has been successful to explain some phenomena in the behavioural economic literature, e.g. procrastination and addition (Harris \& Laibson, 2001), the welfare measured in terms of the utility for society cannot be maximised in a process where the discount rate changes as time moves on (Groom et al., 2005). On the other hand, in a declining model the rate of decline usually adopts hyperbolas and quasi-hyperbolic functions (Ainslie, 1992; Herrnstein, 1961; Loewenstein \& Prelec, 1992; Mazur, 1987) showing much higher discount rates in the 
short-term than in the long-term, when they remain relatively constant. Therefore, to determine the schedule of DDRs it is necessary to make some assumptions concerning the point in time at which uncertainty concerning the discount rate begins (Weitzman, 1998) as well as to calibrate the trajectory that a DDR has to follow from this point (Groom et al., 2005; Newell \& Pizer, 2003).

What is more widely agreed is an arbitrage between exponential discounting and declining discounting through an equivalent SDR, although it appears more useful as a way of determining the maximum ENPV of investments rather to compare different alternatives to solve the same problem (Freeman \& Groom, 2014; Freeman et al., 2015; Groom et al., 2005; Lowe, 2008; Weitzman, 1998). The use of an equivalent SDR is especially adequate where the effects under examination are very long-term and involve very substantial and, for practical purposes, irreversible wealth transfers between different genealogical generations (Lowe, 2008).

In short, there exist different approaches to determine the social value of major investments in infrastructure. They focus on optimising the discounting process to offer "present" decision-makers the most suited value of SDR. According to the time consistency approach, exponential discounting through a constant SDR may be appropriate to determine with rigour the maximum utility of project decisions in the short run (Lind, 1990). For long-term investments, declining discounting by using a DDR or an equivalent SDR is an option that allows taking into account collective preferences over time more adequately (Henderson \& Bateman, 1995). However, whilst this approach can be optimal for the current GPI, it can result in a sub-optimal (time-inconsistent) use of public resources from the perspective of successive governments (Barro, 1999; Karp \& Lee, 2003).

From the former considerations it can be argued that current discount models are not properly analysing the impact of investments implying large timespans and affecting different generations. The simple aggregate of benefits and costs does not offer information about the resulting redistribution of wealth (Bradford, 1997) and, in particular, across the generations affected by the project. Discounting and SDR are useful in CBA to determine the most efficiency alternative for a project from a static present-time perspective, but they appear inadequate to incorporate the interests of future generations, which will undoubtedly be affected by the impacts that present investments in transport infrastructure will have on their welfare.

\section{The generation concept in the IREM model}

Investment projects are typically analysed through a socioeconomic CBA that considers the use of resources, so they are assigned to the period (year) when they are consumed (costs) and generated (benefits). On the other hand, the financial analysis looks at the expected cash flows and at the money inputs and outputs of the various stakeholders, among them the users of the project if they are directly contributing to its financing. The objective is to make sure that funding is available for the implementation of the project and that no major stakeholder will be the subject of financial failure as a consequence of the investment; to ensure financial sustainability. In general, these two analyses are carried out separately and are often improperly mingled.

The welfare considerations, as already mentioned, are made from the perspective of the present generation, but even though the investment resources, such as those used in the construction of the infrastructure, are "lost" by the society in place during the implementation, the actual effects on people's welfare are mostly perceived when they have to pay for these resources either through user charges or through taxes. So, when analysing the fairness of the distribution of actual costs and benefits (welfare) across the generations affected by the project, it is necessary to look on the one hand at the net benefits in terms of resources during the relevant period and the amounts paid during this period for the use of the project (tariffs, tolls, etc.) and as a contribution to its financing, which clearly depends on the funding mechanism applied, in particular the distribution of the public budget used to pay for the investment directly or through loans.

In practice the budget payments for public investments (or private investments requiring public subsidies) are embedded in the public accounts and this is probably why the issue of the fairness of intergenerational distribution has been somehow absorbed by the major problem of the long-term effects of public debt. However, when decisions must be taken at project level, the effects of the funding mechanism on intergenerational fairness seem relevant. To make a proper assessment of these effects across the generations it is necessary to compare the net benefits arising for each of them with the actual payments they make in relation to the project either as users and/or taxpayers. IREM provides a suitable approach to deal with the incorporation of this critical aspect for major infrastructure investments which has not been properly addressed until now.

IREM is a new tool that is useful for decision makers looking for a more balanced distribution between the net socio-economic benefits and the financial burden stemming from long-term projects affecting multiple (overlapped) generations. In the transport sector, the economic lifespan of major infrastructure projects is very long $(20,30,40 \ldots$ years $)$, but properly maintained these types of infrastructures may last indefinitely. A well-designed financing formula, besides ensuring the project's financial sustainability, should arguably ensure intergenerational equity. The IREM model offers a way to analyse the impacts on overlapping generations, meaning the various groups of people, centred around a specific year, that will be affected by the project. The people included in a generation will not change very much in relation to the prior or the next one, as not many people enter or leave society in a year, but after many years the component of a generation will be sensibly different (ISR, 2017).

In this model, the gap between the central year of overlapping generations in of one year. Accordingly, intergenerational redistributive effects are those occurring between annual generations. The main difference between this generational approach and the one used in most scientific papers consists on the meaning of what a generation is. ${ }^{12}$ Typical assumptions for the generational concept (and, by extent, the concept of "intergenerational") in macroeconomic models imply a genealogical meaning without a clear definition of its timespan and, on the other hand, genealogical generations essentially do not overlap. A clear definition is also absent in microeconomic studies, and in studies that aim to assess the implicit distribution in the CBA of the intergenerational preferences of society. However, the concept of overlapping annual generations has an ad-hoc meaning in IREM, including a central year and a timespan.

In the IREM, the concept of annual generation $\left(A G_{i}\right)$ refers to a generation pivoting around a year, $i$, of the project's lifecycle, which incorporates, besides the "society" of year $i$, those of some previous years and those of some of the successive years. As explained before, the non-central "societies" do not have the same members and those who stay as members of the generation have a decreasing interest the farthest they are from the year in which they are observing the project. ${ }^{13}$ This explains the use in the model of a

\footnotetext{
${ }^{12}$ For more details and references see Penyalver and Turró (2017).

13 It is essentially the same argument that justifies the use of the SDR.
} 


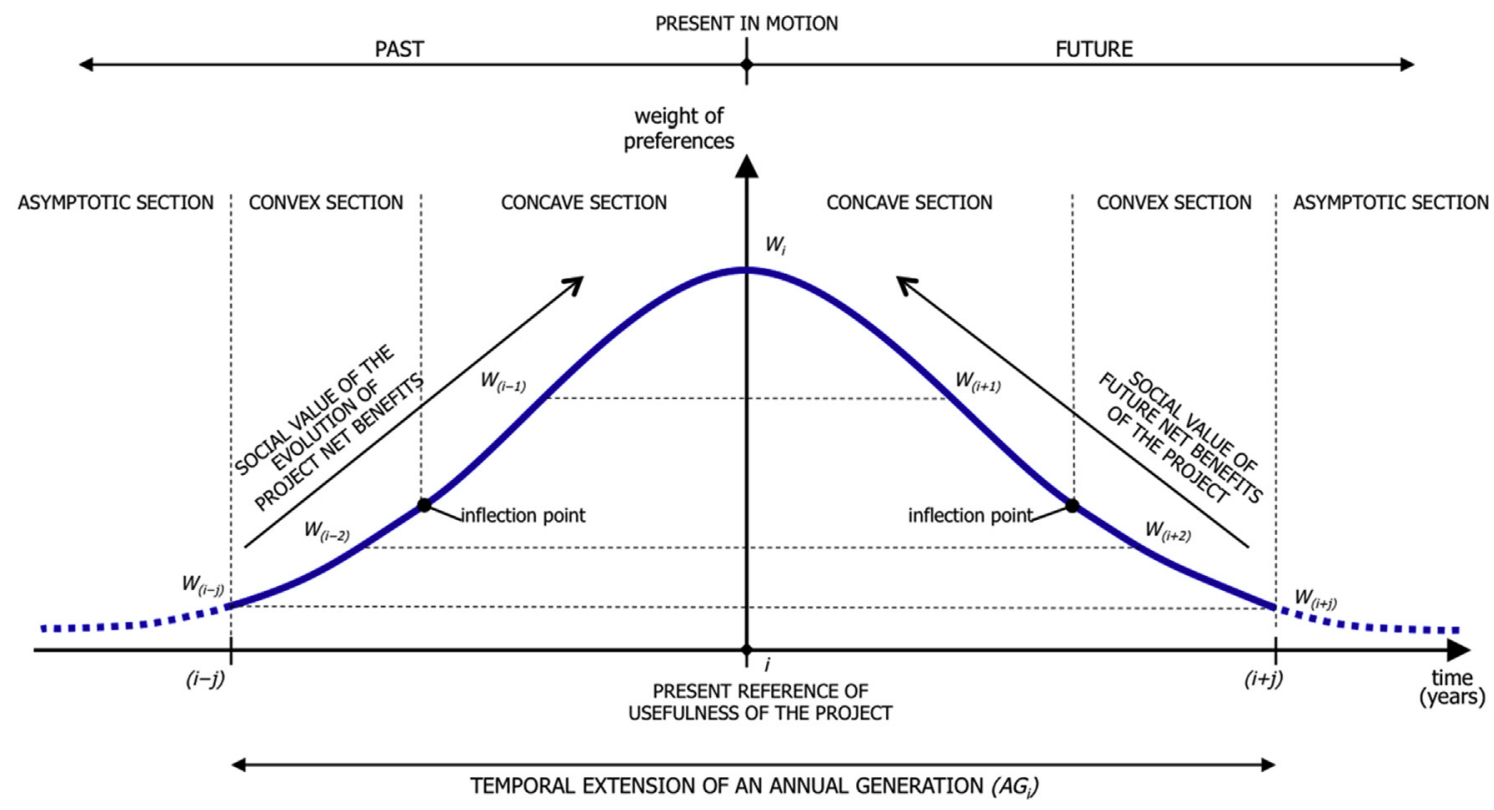

Fig. 2. Conceptual curve of an Annual Generation in the IREM model.

Source: (Penyalver \& Turró, 2017)

theoretical bell-shaped curve to represent the weighted sum of the utilities of a transport project for the society belonging to any given annual generation (cf. Fig. 2).

Indeed, considering year $i$ as the pivotal moment associated to an annual generation, individuals living in that year can assess the value of the benefits and costs, but only part of the effects occurring in preceding or following years. Moreover, although most individuals in year $i$ have already been affected by the project in previous years and they will probably continue to be affected in the future, they are less numerous and subject to more uncertainties as they find themselves farthest from the pivotal year.

Fig. 3 below shows that the curve function (onwards, the weighting curve) for an annual generation keeps the highest utility of transport infrastructure projects in the short-term for society living in the present (central) year in comparison to the long-term. From this pivotal year $(i)$, the weighting curve for the years included in the generation slopes down on both sides. Because the economic preferences of the agents in the generation reach, logically, their maximum in the central year.

Taking as time reference the moment of decision to build, the intergenerational impact analysis in IREM is performed from the perspective of a "present in motion" where the investment has not been happened yet. It is assumed that only individuals living in the central years of the future generations affected will really know what finally occurred, so risk perception should be similar for both current decision-makers and future generations concerned by its impacts (cf. Fig. 3).

Finally, a critical difference of the IREM with other economic approaches is that the function represented by the weighting curve includes, for each year within an annual generation, both past and future project-related effects.

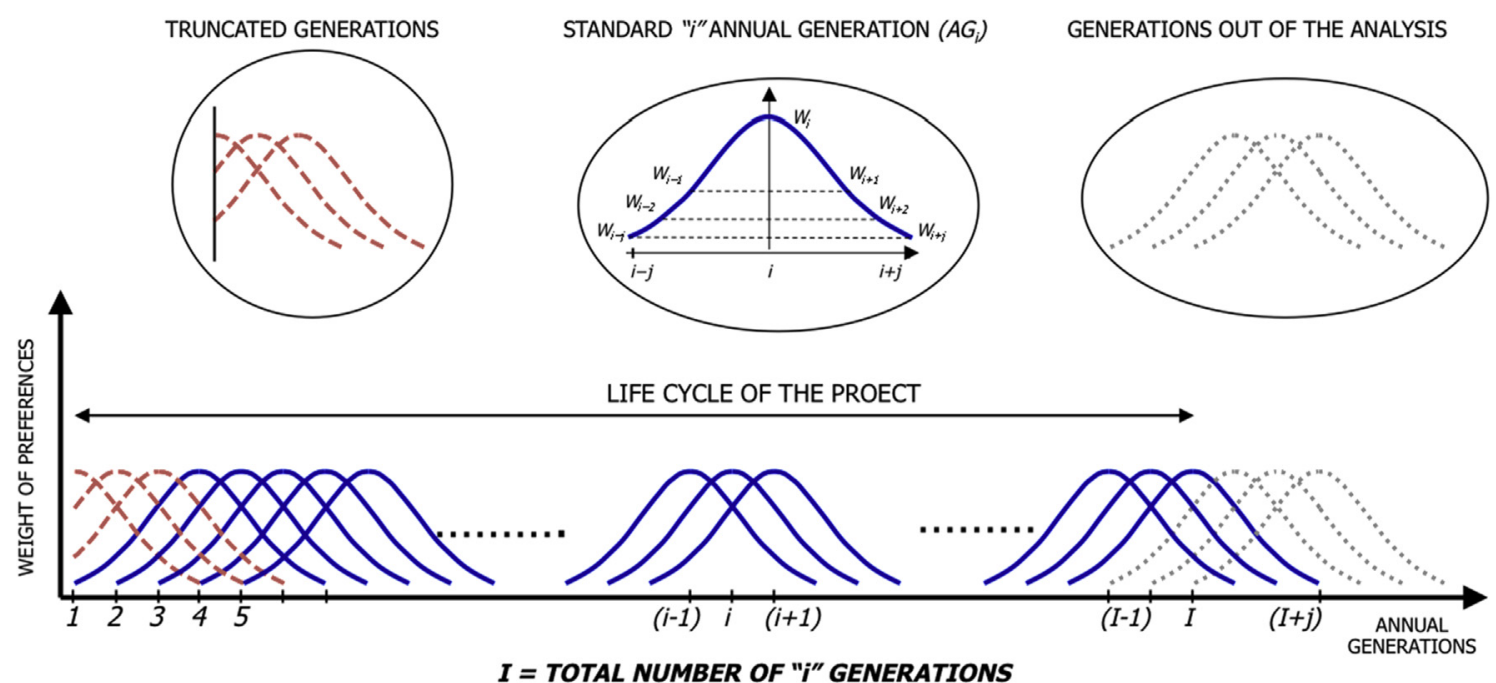

Fig. 3. Generational assessment of the inter-annual differences between costs and benefits. Source: (Penyalver \& Turró, 2017) 


\section{Assessment of the population's time preferences}

A major aspect of the research was to define a theoretical function for the weighting curve in the IREM. Conducting an ad-hoc survey was considered the best way to design a representative function. It was designed with the purpose of determining the importance of major transport infrastructure projects for individuals living in a specific year and how they would appreciate them when they saw them far from the central year in which they were living. In a hypothetical scenario given to respondents, this importance was reduced the further they were placed from the central year of the annual generation. The resulting weighting curve was expected to represent people's perceptions and preferences related to the relevance of past and future project-related effects in their present welfare.

Survey research is one of the most important sources of gathering data in the applied social sciences (Groves et al., 2009). When survey questions have high reliability, they allow to measure opinions, attitudes and behaviours (Alwin, 2007). Nevertheless, measurement error is an inherent component of survey research, and survey questions are imperfect representations of the concepts they intent to measure (Biemer et al., 2011). In our case, the development of the measurement instrument (questionnaire) was based on current best practices in survey research. In order to minimise measurement error properly, it was followed a three-step procedure to design survey questions (Saris \& Gallhofer, 2014). In the first step, the concepts to be measured were defined in detail. In the second step, specific statements derived directly from the concepts were developed. In the third step, we included in the statements all the elements that the questions should have, for instance, contextual clues, and, finally, they were transformed into survey items. The first survey item included an introduction with explanations about the hypothetical infrastructure investment and related definitions, the question stem, a numeric response scale and a visual aid for an online survey which included a map pointing out the places affected by the new infrastructure.

The questionnaire was developed with the idea to be administered in an online access panel. Both the infrastructures of reference and the members of the panel were located in Catalonia. Respondents were asked to choose the language of the survey between Catalan and Spanish. It was divided into five blocks and each block had an introduction. In the first block, the survey was presented with a short description of its purpose. The second block described two highway infrastructure projects (the "Eix Transversal" and the "Forth Ring Road"). The third block included questions that represented control variables to detect differences in the profiles of respondents, e.g. questions related to mobility behaviour. The fourth block introduced an explanation to aid the respondent answering questions about their preferences over the transport infrastructure projects. Finally, in the fifth block, the concepts of interest were asked.

The survey was administered through the NetQuest commercial online access panel in February 2016. Participants in the panel are recruited by invitation. As they participate regularly in the panel, their socio-demographic information for quota sampling is already known. The sample for this survey consisted of individuals over 18 years old living in the four provinces of Catalonia (Barcelona, Girona, Lleida and Tarragona). They were randomly selected based on demographic quotas that mirror the characteristics of the population. Upon full completion of the survey, respondents received points that give access to gifts. The total number of completed interviews was 208. The data was analysed to define the time span of an annual generation and to establish the weights for a theoretical weighting curve. Analyses were conducted using R Studio v 0.99 .893 , user's interface for $\mathrm{R}$ statistical environment. (RStudio
Team 2015).

The generation concept was incorporated in the survey by means of a question relating both to the respondents' economic behaviour and their perception on how society should repay the investment (onwards, control question). This question confirmed whether respondents understood the concept of generation or not:

«Now, imagine that the third lane of the C25 motorway project is open in 2020: Which one of the following groups of people should bear the largest part of the public expenditure that this investment entails?»

\section{A. People living in Catalonia when the project's construction starts} (before 2020).

B. People who will live in Catalonia from 2020 on, after the project is commissioned.

C. People living in Catalonia during and after the project's construction.

D. People living in Catalonia before, during and after the project's construction.

In order to estimate the time span of a transport infrastructure investment, the survey presented a vignette describing a hypothetical investment that consisted in adding the third lane in an already existing motorway (Eix Transversal of Catalonia C-25). Respondents were given a detailed description of the project including a map. The project would be implemented from 2016 and would be commissioned in 2020. In this hypothetical situation, respondents were public officers, responsible of deciding which was the most suitable time span to finance the investment (a number from 0 to 100 years). The question, translated into English, was as follows:

«For how long, do you think, the Catalan Government should spend public money from its annual budget in this investment?»

This question was used to establish a time span that allowed estimating the yearly importance weights in the annual generation. Following the results of the survey's pre-test phase, we fixed the investment's time span in the questionnaire in nine-years. Pretesting results indicated that an odd number better reflected a generation centred around the commissioning year of project. It also showed that a generation covering a slightly longer period that the first one proposed ( 7 years) would be better adapted to represent everyone's perceptions. Next, respondents were asked to imagine they were in 2020. Taking this year as a reference, they rated on a score from 0 to 10 points the importance of the infrastructure project's effects over time, in comparison to the value they assigned to the central year (2020).

The participants in the survey were asked to rate first the central year (2020). Then, they could rate the importance of the project's impact in pairs of years (2019-2021, 2018-2022, 2017-2023 and 2016-2024). This provided them with the stimuli to understand that they could rate the social impact of the project in a different way depending if the year they rated preceded or followed the opening of the motorway extension. The aim of presenting a project that would expand an existing motorway was to make respondents aware that infrastructure investments convey potential social effects and to make them familiar with the rating mechanism. This facilitated the repetition of the exercise presenting a second scenario, a new motorway in the public agenda of Catalonia, the "Forth Ring Road" (B40 motorway) that has been discussed for a very long time. As the IREM is expected to be used in decision-making 
processes of infrastructure investments, this case presented an illustration of its potential use in a real situation.

Despite following best practices in survey research to develop the survey measures used for this case, answering about hypothetical scenarios may be a difficult task for some respondents. Actually, it should not be excluded the possibility that respondents rated the importance of the project's impact considering their present situation, not a future one. However, research suggests that judging concrete scenarios, even if hypothetical, can be closer to judging real daily life events (Alexander \& Becker, 1978; Beck \& Opp, 2001). Therefore, by presenting very concrete scenarios, respondents in the survey were able to form an opinion on the subject under investigation. Results presented below show high variability in the data when sub-samples of different sociodemographic characteristics were analysed, being an indication that different profiles of respondents had indeed a different opinion.

The first outcome of the survey data analysis was the estimation of the time span. Fig. 4 shows that the average value was 8.4 years ( $s d=10.7)$, which should be interpreted as the average number of years survey respondents thought an infrastructure should be fully paid in. ${ }^{14}$ The long tail indicated a large variability on perceptions about how public money should be managed and spent. By analysing sub-samples of different age cohorts, different cities classified according to their population range, among other indicators, we found significant differences among some sub-groups for both, the average time span and its standard deviation.

We divided the total sample in four groups (A, B, C and D) corresponding to respondents' answer on whom should bear the project's costs. ${ }^{15}$ Within each sub-sample, we obtained similar time span values and similar tails for density traces (Fig. 5). This indicates that citizens' opinion about public money management differs after controlling for age, sex, place of residence, etcetera.

The second part of the survey data analysis aimed at estimating the importance of weights given to each year included in an annual generation, $A G_{i}$. As already mentioned, a time span of 9 years was fixed in the questionnaire. Respondents' scores were transformed to obtain a standard scale and compare among all of them. As respondents were asked to rate on a score from 0 to 10 each year within a time span of 9 years, the resulting data allowed comparing respondents' preferences year-on-year within the time span, but it did not allow statistical analysis for the whole sample (because the total amount of points differ for each respondent). Therefore, for each respondent, every set of yearly scorings in the time span was divided by the maximum score given by the same respondent. In all cases, this maximum corresponded to year 5 , the central year in the questionnaire's time span. We kept out the respondents' answers when they scored zero at any year in the time span (11.3\% respondents in the survey item about the B-40 motorway project). Onwards, we refer to the set of the resulting valid outputs as respondents' adjusted scoring.

We looked at the correlation of the whole set of sociodemographic control variables in the survey with the respondents' adjusted scoring. Particularly, we found that the "age cohort" and "control question" variables had an important influence in the respondents' scoring. Information about the place of

\footnotetext{
14 Two extreme values both with a timespan $=99$ years were dropped from the analysis.

15 According to the options A D in the survey, respondents had to decide what generations of taxpayers in Catalonia ought to foot the bill of the project: A) taxpayers, during the construction phase; $\mathrm{B}$ ) taxpayers, from the commissioning of the project onwards; $\mathrm{C}$ ) taxpayers living in Catalonia during and after the construction phase; D) the same that $\mathrm{C}$ ) and, in addition, generations of taxpayers living even before the construction phase.
}

residence, gender, language of the survey, etc. did not show significant differences among classes. Moreover, disaggregating to further levels resulted in very small sub-samples without statistical power.

Once we identified the main variables conditioning respondents' outputs, it was possible to disaggregate the sample's yearly scores and to calculate the main statistical indicators in each year within the time span. Fig. 6 shows a low dispersion in the respondents' adjusted scoring obtained at every age cohort, regardless of their response to the control question ("control" in the Figure's label). We found a similar pattern for all the years in the timespan (cf. Table 2).

The yearly average for the respondents' adjusted scoring within the time span of 9 years is a reliable indicator of the respondents' preferences for both the B40 and the C25 motorway projects. As shown in Table 2, the value of the yearly median and the standard deviation for the average confirmed that the yearly average for the respondents' adjusted scoring represents the collective preferences in the sample.

By taking into account the trends and patterns represented by the yearly increments or decrements in the importance values, it can be analysed how people's preferences change over time. Our results show that from the year of reference (2020) to the future, respondents' adjusted scoring decreases in the short run. Between the year 5-6, this decrement is three times bigger than in the long run (years 6-9). For typical discounting models reflecting consumers' preferences it implies that the SDR should decline at a higher rate in the short term that over longer time horizons. This pattern, indicating that consumers' preferences for major transport projects change over time, is actually a major finding of this research because it puts into question a basic hypothesis of the rational choice theory. A second conclusion is that, from the past to the year of reference, the rate of change in the respondents' adjusted scoring increases almost twice at years 4 and 5 (2016 and 2017). This pattern implies that choice behaviour is not very consistent over long time horizons.

Our findings show that when respondents were asked to take decisions that would affect them and the rest of the society they lived in, they still prefer earlier benefits to later ones. The overall pattern of responses confirms that individuals care more about consumption effects in their welfare in the short term (years around the year of reference) than about benefits before or after the reference year. This finding implies that the property of time consistency assumed in discounting models does not hold for preferences about investments in transport infrastructure.

The next step was to determine the most suitable function, $F(t)$, to represent the weighting curve in the IREM within the and the corresponding length of a standard annual generation. The results of the survey suggest that any curve adapted to the IREM's definition of annual generation should have two different branches. The first one increasing from the past to the pivotal year of reference $i$, and a second one decreasing from this year $i$ to future time units. Most probabilistic functions follow this pattern and many of them are non-symmetrical. They can be defined by three shape parameters $(a, b, c)$ : one that determines that the highest value in the curve occurs for the pivotal year of reference (year 5 within the time span of the survey); a second one determines this value (in the pivotal year); and, the third one determines the rate of declining for the curve.

We estimated the best fitting curve according to the value of the respondents' adjusted scoring for every year and the pattern of increments and decrements described by the survey data. The points representing those values were plotted and taken as benchmarks to validate the probabilistic curve. The theoretical symmetrical features for the curve considered in the IREM 


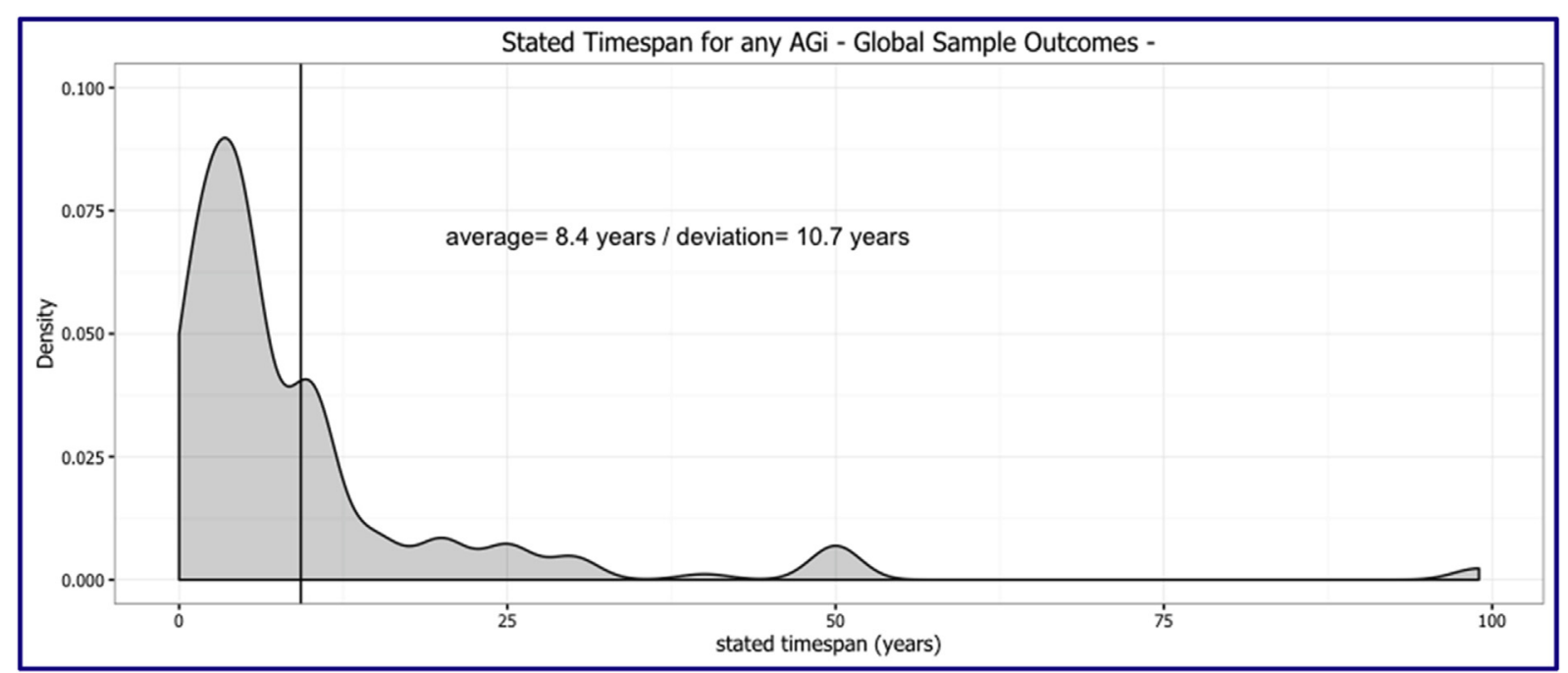

Fig. 4. Density Trace of the 'stated timespan' for the global sample.

Source: Authors

(Penyalver \& Turró, 2017) were not well adapted to the benchmark intervals resulting from the survey, as can be seen in the chart in Fig. 7 below. The gradient for the branch from the past to the central year of reference should be stronger than the gradient from this pivotal year to the future. Therefore, the theoretical model was adjusted empirically in order to adapt it to the best fitting curve, exploring several options, among them a Gaussian, a Gumbel and a Weibull function.

After exploring and rejecting Gaussian and Gumbel probability functions to adjust the weighting curve $F(t)$ linked to a standard generation, ${ }^{16}$ the Weibull probability function ${ }^{17}$ appeared as quite adequate, given the non-symmetrical attenuation of the yearly weights within a non-determined time span and the possibility of adjusting a shorter branch from the past to the pivotal year. To find the best fit for the curve, we took the central year of reference in the time span in the survey questions (2020), which corresponded to the year with the maximum in the respondents' adjusted scoring. We assumed that the pattern of mitigation i.e. the weights' yearly attenuation from the pivotal year, could be represented by percentage weights, ${ }^{18} w_{j}$, decreasing through time. For $t>0$, the gradient of the respondents' adjusted scoring represented by the function $F(t)$ declines more strongly in the short term than in the long term. Fitting a Weibull function required imposing the following boundary conditions:

A. The curve reached its maximum at the pivotal year in the time span. According to the empirical data from the survey, this corresponds to year 5 .

B. From the pivotal year to the past, at year $j-4$ the function's value corresponded to the minimum of the respondent's adjusted scoring. The scoring at year $j-5$ should be as close to zero as possible.

\footnotetext{
${ }^{16}$ The methodology followed to fit and reject the Gaussian and the Gumbel probability functions is documented in the Appendix attached.

17 The Weibull function also behaves as a non-exponential rate of decline function when $t>0$, therefore, it will tend to decrease strongly in the short term more than in the long term.

18 Percentage weights correspond to people's preferences over costs and benefits occurring either before or after the 'pivotal year' of a standard annual generation.
}

C. According to the time span's statistical outcomes (average $=8.4$, $\mathrm{sd}=10.7$ years), the future branch would not go beyond year $j+10$.

D. The weighted respondents' adjusted scoring predicted with the parametric function for the year $j-4$ was a comparative reference to identify the limit for the time span in the curve from the pivotal year onwards.

Fig. 7 shows the adjusted curve representing the shape and pattern of the empirical data.

The equation for the Weibull function obtained from the curve plotted in Fig. 7 shows that the number of years defining the time span of a standard generation was the range between a scoring equal to 3.4 at year $j-4$, and the year with a similar value to the future of the reference year, $j+10$, (3.3 points), therefore, the time span of the generation was set at 15 years (cf. Table 3 ).

Next, we determined the scoring corresponding to every year within the aforementioned time span of 15 years and the corresponding year-on-year variation. The predicted yearly scoring at each year within the time span fitted the pattern obtained by the respondents' adjusted scoring in the survey for a 9 years time span. This implies that individuals' preferences in the very short-term, either from the year of reference to the future or to the past are well represented by the gradients of change shown by the curve in Fig. 7.

We calculated the percentage weights for each year within the $A G_{i}$ with a simple transformation from the predicted-scorings, finally defining the weighting curve for any standard generation with a 15-year time span (cf. Fig. 8).

As in the IREM the concept of generation is strictly linked to the individuals affected by the project, and this concept reflects how important a transport project is for the society belonging to a same period of time within the lifecycle of the project (no matter the moment of the analysis), we conclude that a Weibull weighting curve (imposing the boundary conditions, $A \sim D$ ), correctly reflects the weights given by the respondents of the survey to their appreciation of both transport projects. Table 4 shows that the nonsymmetrical theoretical weighting curve and its parametric function adopted are suitable to reflect how significant the effects of a transport project are for a society's welfare within a standard generation spanning over a 15 -year time span.

According to the society being analysed, the values in Table 4 

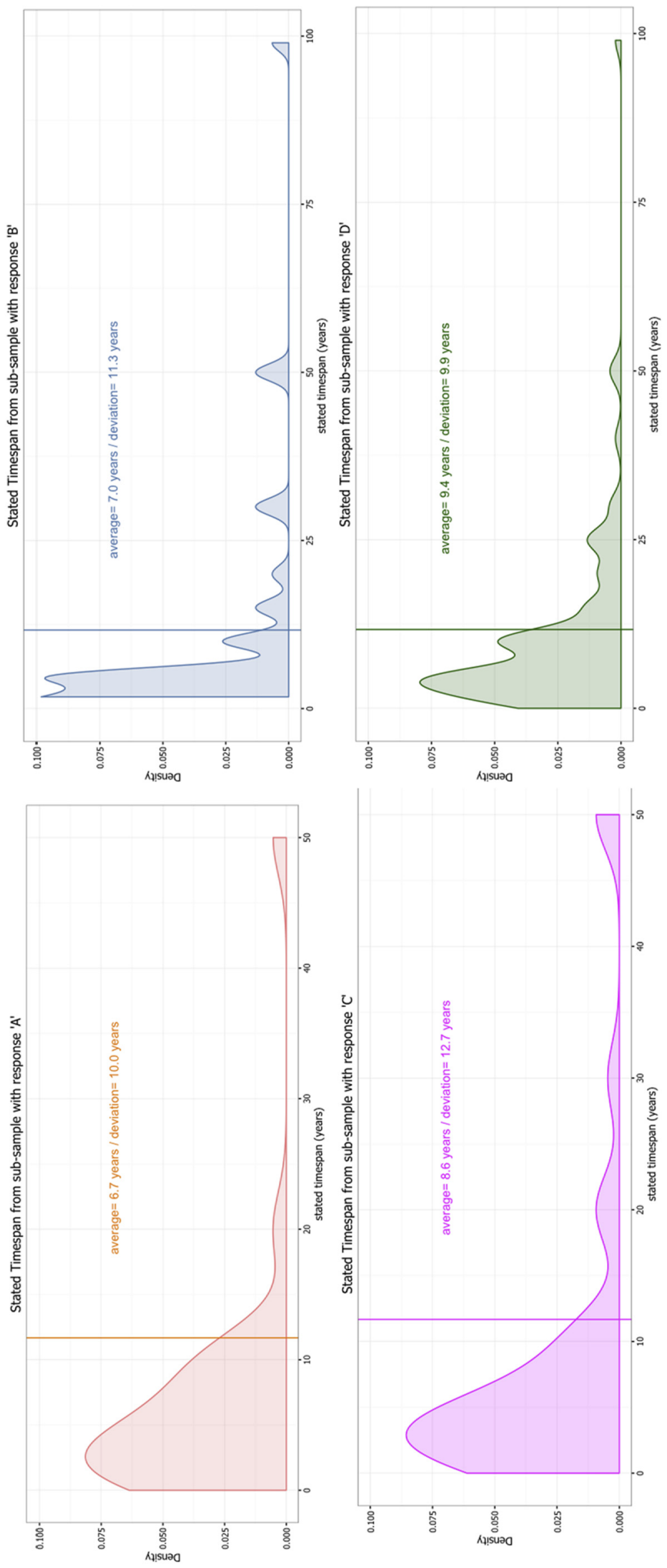

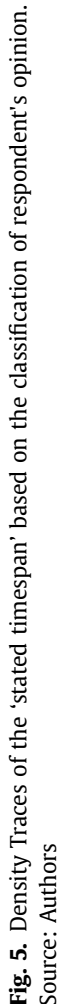




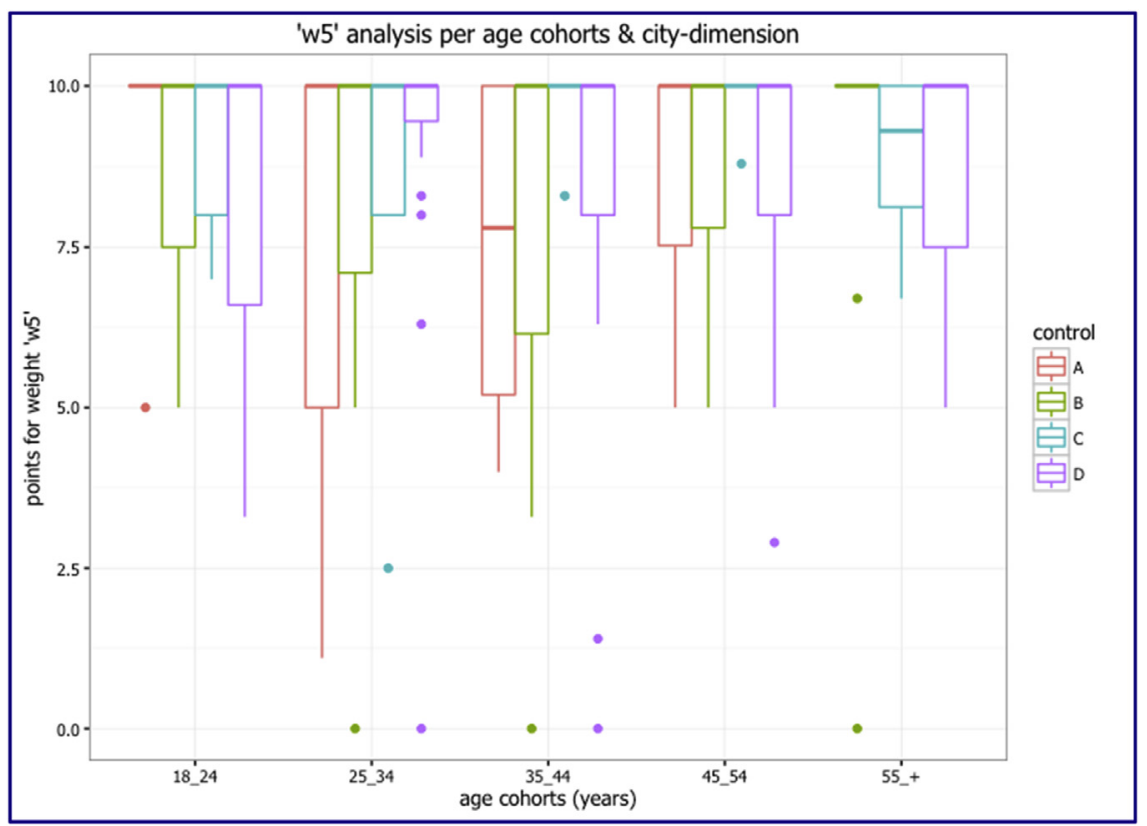

Fig. 6. Box Chart for the respondents' adjusted scoring in year 5.

Source: Authors

Table 2

Yearly-average for the respondents' adjusted scoring within a timespan of 9 years.

\begin{tabular}{|c|c|c|c|c|c|c|c|c|c|}
\hline \multirow[t]{2}{*}{ Timespan of 9 years } & \multicolumn{9}{|c|}{ Average for the adjusted scoring } \\
\hline & year 1 & year 2 & year 3 & year 4 & year 5 & year 6 & year 7 & year 8 & year 9 \\
\hline Median & 6.00 & 6.70 & 7.80 & 8.60 & 10.0 & 8.70 & 8.30 & 8.55 & 10.0 \\
\hline Average & 5.62 & 6.22 & 6.90 & 7.54 & 8.61 & 7.72 & 7.41 & 7.00 & 6.68 \\
\hline Standard deviation & 4.06 & 3.63 & 3.23 & 3.01 & 2.44 & 2.82 & 3.03 & 3.47 & 3.96 \\
\hline Yearly increment $(+) /$ decrement $(-)$ & - & +0.62 & +0.68 & +0.64 & +1.07 & -0.89 & -0.31 & -0.39 & -0.32 \\
\hline
\end{tabular}

Source: Authors.

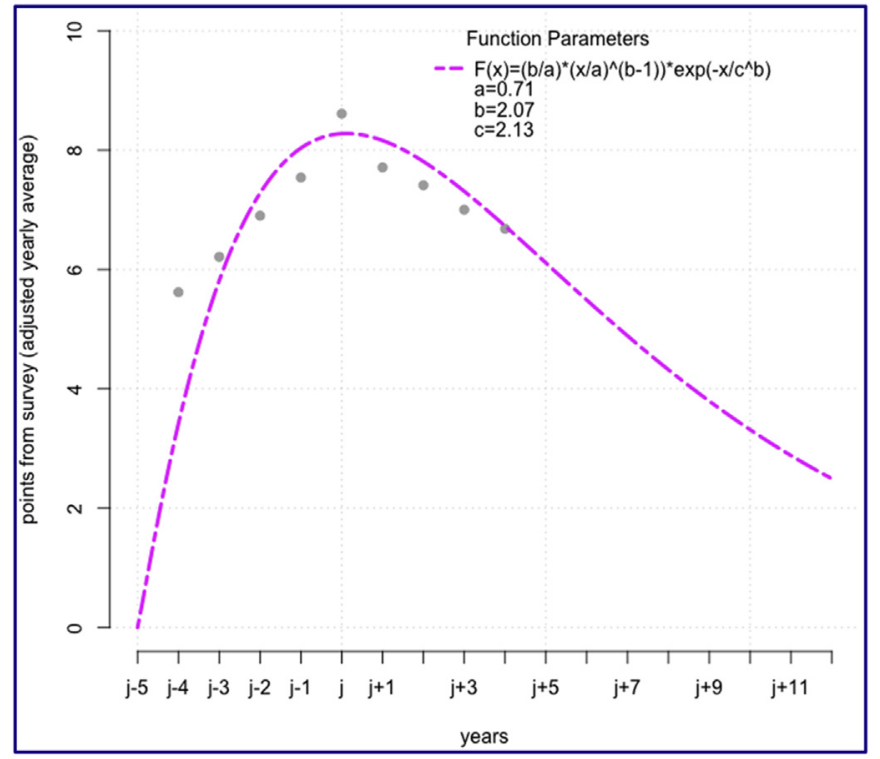

Fig. 7. Curve fitting from a Weibull function. Source: Authors cannot be considered as fixed for any IREM application, which should probably be adapted to the society being analysed. The methodology to obtain the relevant values appears, however, as robust and generally applicable. IREM has been applied and is currently being used in a wider research aiming at analysing the intergenerational impact of particular case studies as well as part of a comprehensive methodology to detect white elephants ${ }^{19}$ in the transport sector.

\section{Conclusions}

The paper explains the reasons why a fair decision-making process to invest in major infrastructure projects should consider its real effects on future generations. Whilst exponential discounting and typical SDR are appropriate to estimate the social value of public investments from the perspective of the generation deciding whether or not to carry out the project, they are not neutral to reflect the social interest of projects implying very large timespans. Indeed, the results from this research show that consumers' preferences for major transport projects change as time moves on, which would support the use of declining discount rates (DDRs) to estimate the social value of long-term investments through CBA. This also supports the basic hypothesis of our

\footnotetext{
19 This concept is mostly used in relation to public investments representing a severe misallocation of society's resources and, as a consequence, expenditures that
} can be deemed to reduce the wellbeing of its future members. 
Table 3

Predicted yearly-scoring for a 15 years timespan from a Weibull curve.

\begin{tabular}{|c|c|c|c|c|c|c|c|c|c|c|c|c|c|c|c|c|c|c|c|}
\hline $\begin{array}{c}\text { TIMESPAN OF } \\
15 \text { YEARS }\end{array}$ & \multicolumn{11}{|c|}{ ADJUSTED YEARLY AVERAGE OF THE RESPONDENTS' SCORING } & TOTAL \\
\hline Scoring $^{*}$ & 3.4 & 5.8 & 7.3 & 8.0 & 8.3 & 8.2 & 7.8 & 7.3 & 6.7 & 6.1 & 5.5 & 4.9 & 4.3 & 3.8 & 3.3 & 90.7 \\
\hline $\begin{array}{c}\text { Yearly increment } \\
(+) / \text { decrement }(-)\end{array}$ & 3.4 & 2.4 & 1.5 & 0.7 & 0.3 & -0.1 & -0.4 & -0.5 & -0.6 & -0.6 & -0.6 & -0.6 & -0.6 & -0.5 & -0.5 & --- \\
\hline
\end{tabular}

${ }^{(*)}$ Values calculated from the parametric function shown in Figure 7 above.

Pink colour highlights maximum values in the series, whilst yellow colour highlights minimum values.

Source: Authors

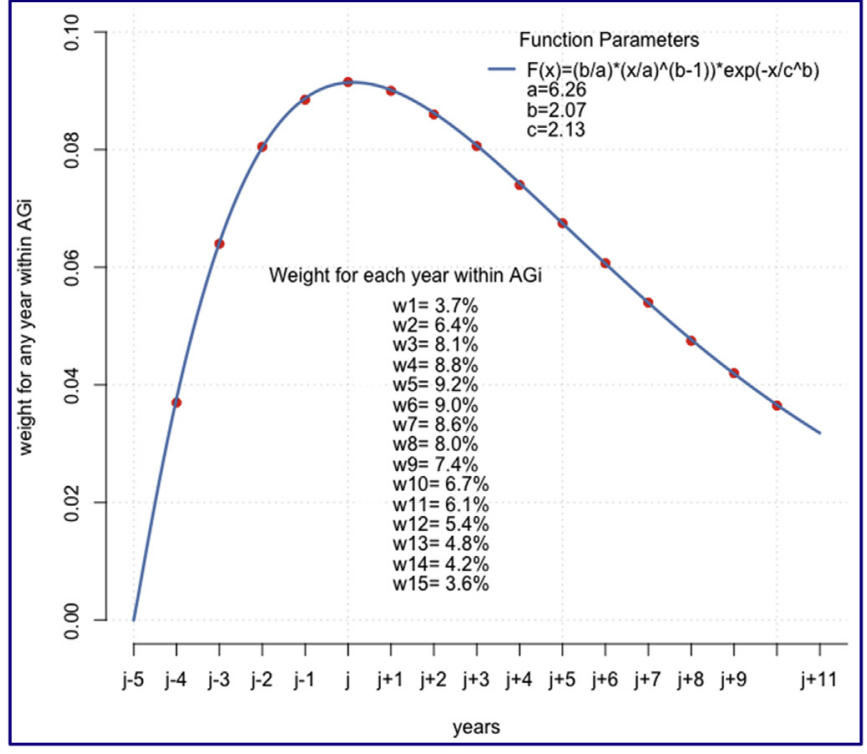

Fig. 8. Weighting Curve for any standard Annual Generation (AGi) of 15 years. Source: Authors research line, which states that the present practice to appraise major projects does not take sufficiently into account their impacts on future generations.

The "Intergenerational Redistributive Effects Model" (IREM) model offers a way to incorporate in the decision-making process of a major project its intergenerational impacts. The model provides indicators that compare the net benefits with the real financing burden for overlapping generations, meaning the various groups of people around a specific year, that will be affected by the project. This analysis is complementary to the CBA and provides a view of the fairness of the actual financial payments for the project across the various generations affected.

The first aim of the research presented in this paper was to empirically define the function to be used as a weighting curve in IREM. To determine this function and the timespan of a standard generation required a specific survey with an innovative design in order to place the respondents in a future situation from which they were asked to value the impacts of an infrastructure project in the past and in the next few years. This survey was conducted in Catalonia and in relation to well-known transport projects. The data collected were of good quality and used, in a complex fitting exercise, to establish the timespan for any "standard generation" in 15 years for major investments in transport infrastructure, and to propose the weighting curve shown in Table 4 using a Weibull distribution. The values obtained cannot be considered as fixed for any IREM application, which should probably be adapted to the society being analysed. The methodology to obtain the relevant values appears, however, as robust and generally applicable.

Table 4

Weights in a Weighting Curve for any Annual Generation of 15 years.

\begin{tabular}{|c|c|c|c|c|c|c|c|c|c|c|c|c|c|c|c|}
\hline GENERATION & 1 & 2 & 3 & 4 & 5 & 6 & 7 & 8 & 9 & 10 & 11 & 12 & 13 & 14 & 15 \\
\hline Standard (4+11 years) & 3.7 & 6.4 & 8.1 & 8.8 & 9.2 & 9.0 & 8.6 & 8.0 & 7.4 & 6.7 & 6.1 & 5.4 & 4.8 & 4.2 & 3.6 \\
\hline${ }^{* *}$ Truncated (3+11 years) & - & 6.6 & 8.4 & 9.1 & 9.6 & 9.3 & 8.9 & 8.3 & 7.7 & 7.0 & 6.3 & 5.6 & 5.0 & 4.4 & 3.7 \\
\hline${ }^{* *}$ Truncated (2+11 years) & - & - & 9.0 & 9.8 & 10.2 & 10.0 & 9.6 & 8.9 & 8.2 & 7.5 & 6.8 & 6.0 & 5.3 & 4.7 & 4.0 \\
\hline${ }^{* *}$ Truncated (1+11 years) & - & - & - & 10.8 & 11.2 & 11.0 & 10.5 & 9.8 & 9.0 & 8.2 & 7.5 & 6.6 & 5.9 & 5.1 & 4.4 \\
\hline${ }^{* *}$ Truncated (0+11 years) & - & - & - & - & 12.6 & 12.3 & 11.8 & 11.0 & 10.1 & 9.2 & 8.4 & 7.4 & 6.6 & 5.8 & 4.9 \\
\hline
\end{tabular}

${ }^{(*)}$ In the weighting curve for the standard annual generation of 15 years the "year of reference" is year 5 .

${ }^{(* *)}$ The weights for the truncated annual generations have been calculated by sharing out proportionally the excluded weights among the rest of weights in the corresponding truncated annual generation.

Pink colour highlights maximum values in the series, whilst yellow colour highlights minimum values.

Source: Authors 
The results presented here have been essential for a proper application of the IREM model to several transport infrastructure projects, funded with different mechanisms. The IREM indicators obtained show the strong influence of the project financing models on intergenerational impacts and thus the need to incorporate the financing mechanisms and their implications for future generations into the project appraisal procedures.

\section{Acknowledgments}

This research was financially supported by the European Investment Bank through the STAREBEI Programme. The authors want to thank the EIB for its support and, in particular the EIB Institute staff who have channelled the fellowship. The findings, interpretations and conclusions presented in this article fall entirely under the responsibility of the authors and should not be attributed in any manner to the European Investment Bank. We also thank an anonymous reviewer for insightful comments on an earlier draft. Any remaining errors are the authors' responsibility.

\section{Appendix A. Supplementary data}

Supplementary data related to this article can be found at https://doi.org/10.1016/j.retrec.2017.11.001.

\section{Appendix}

In order to define $F(t)$, we first tested a Gaussian parametric function because it represented our theoretical expectations. We estimated a symmetric curve from a central (pivotal) year declining to both past and future years following the same pattern. To adjust the curve, we took the central year of reference in the time span in the survey questions (2020), which corresponded to the year with the maximum in the respondents' adjusted scoring. We assumed that the pattern of mitigation i.e. the weights' yearly attenuation from the pivotal year, could be represented by percentage weights ${ }^{20}, w_{j}$, decreasing through time. For $t>0$, the gradient of the respondents' adjusted scoring represented by the function, $F(t)$, declines more strongly in the short term than in the long term.

It was assumed that the Gaussian parametric function would reach values close to zero at the years outside the time span. Moreover, during the years before year $j-4(j-5, j-6, \ldots)$ we assumed that people would be highly unconcerned about the project's early stages, such as planning, design, procurement. Actually, those early stages of investments in transport infrastructures could last several years. Following the same logic, values for years after $j+4(j+5$, $j+6, \ldots)$ should be close to zero. During the length of the generation time span, i.e. between the year $j-4$, and the year $j+4$, values would match the ones obtained in the survey data life span (average $=8.4$ years).

The value for parameters $a$ and $c$, were determined by successive approximations to plot a Gaussian curve of the respondents' adjusted scoring yearly-average from year $j-4$ to $j+4$. Figure A.1 shows the resulting function and the values for its parameters. Grey points represent the respondents' adjusted scoring from the survey data. The plot indicates that a Gaussian function did not adjust correctly the data. Therefore, we concluded that a Gaussian function does not represent the social preferences for investments in transport infrastructure projects obtained from the data.

\footnotetext{
20 Percentage weights correspond to people's preferences over costs and benefits occurring either before or after the 'pivotal year' of a standard annual generation.
}

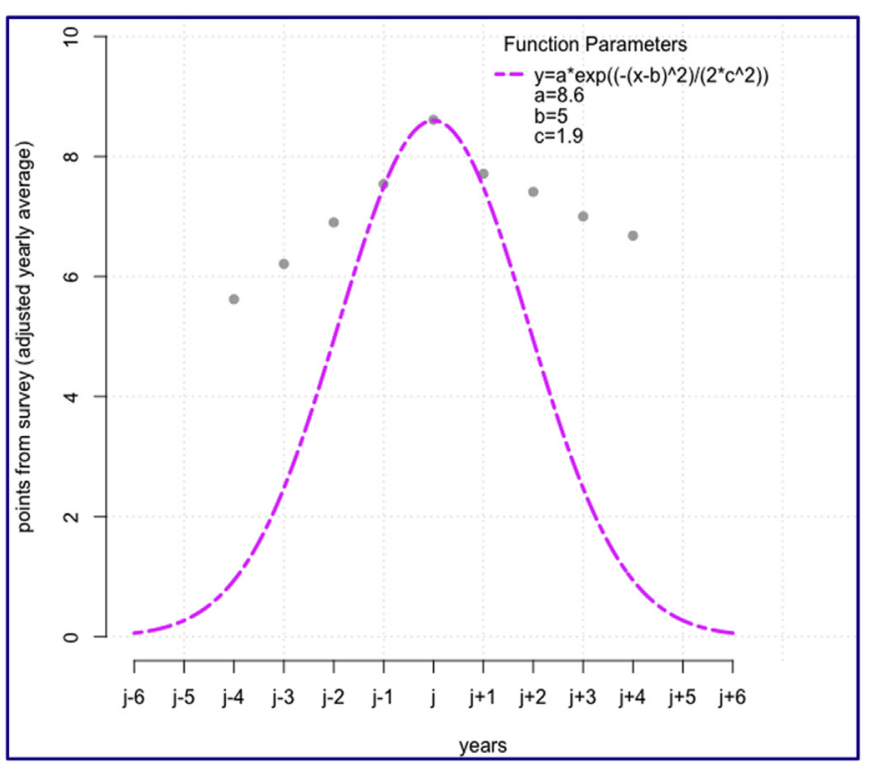

Figure A.1. Curve fitting from a Gaussian function.

Source: Authors

As the Gaussian function did not fit the data, we tested a Gumbel $^{21}$ function to adjust the weighting curve linked to a standard generation. This allowed us to test a non-symmetrical attenuation of the yearly weights within a non-determined time span. Unlike our previous fitting of a Gaussian curve for which we aimed at drawing a symmetrical curve for a pre-defined time span of 9 years, the Gumbel function requires to calculate the parameters for a non-symmetrical probabilistic function with the following boundary conditions $(\mathrm{A} \sim \mathrm{D})$ :

A. First, the curve reached its maximum at the pivotal year in the time span, according to the empirical data from the survey this corresponds to year 5 .

B. From the pivotal year to the past, at year $j-4$, the function's value corresponded to the minimum of the respondent's adjusted scoring. The scoring at year $j-5$, should be as close to zero as possible.

C. According to the time span's statistical outcomes (average $=8.4$, $\mathrm{sd}=10.7$ years), the future branch would not go beyond year, $j+10$.

D. The weighted respondents' adjusted scoring predicted with the parametric function for the year $j-4$, was a comparative reference to identify the limit for the time span in the curve from the pivotal year onwards.

Figure A.2 shows the Gumbel curve fitted to estimate the function parameters. To define the time span of a generation using this function we used the adjusted scoring for the year $j-4$, of 2.4 points. Unlike the Gauss curve, where this value matches the respondents' adjusted scoring in $j+4$, the Gumbel curve conditions outlined above required estimating the adjusted scoring for the years following the pivotal year. We identified the adjusted scoring in future time observations at $j+7,(2.3$ points) matching its counterpart in past observations at $j-4$ (cf. Table A.1). Accordingly, the time span was set in 12 years for a Gumbel function; 4 years for the branch from the past to the pivotal year and, 8 from the pivotal year to the future.

\footnotetext{
$\overline{21}$ Gumbel functions also behaves as a non-exponential rate of decline function when $t>0$, therefore, it will tend to decrease strongly in the short term more than
} in the long term. 
Table A.1

Predicted yearly-scoring from a Gumbel curve.

\begin{tabular}{c|c|c|c|c|c|c|c|c|c|c|c|c|}
\hline \multirow{2}{*}{$\begin{array}{c}\text { TIMESPAN OF } \\
\text { 12 YEARS }\end{array}$} & \multicolumn{1}{|c|}{ ADJUSTED YEARLY AVERAGE OF THE RESPONDENTS' SCORING } \\
\cline { 2 - 17 } & $j-4$ & $j-3$ & $j-2$ & $j-1$ & $J$ & $j+1$ & $j+2$ & $j+3$ & $j+4$ & $j+5$ & $j+6$ & $j+7$ \\
\hline Scoring $^{*}$ & 2.4 & 4.5 & 6.6 & 8.0 & 8.4 & 8.0 & 7.2 & 6.0 & 4.9 & 3.9 & 3.0 & 2.3 \\
\hline
\end{tabular}

${ }^{(*)}$ Values calculated from the parametric function shown in Figure 7 below

Pink colour highlights maximum values in the series, whilst yellow colour highlights minimum values.

Source: Authors

As in the case of a Gaussian function, a Gumbel function did not fit to represent the society's preferences for investments in transport infrastructure projects. As it is observed in Figure A.2, the Gumbel curve does not match the empirical benchmarks representing the adjusted yearly scoring obtained from the survey data.

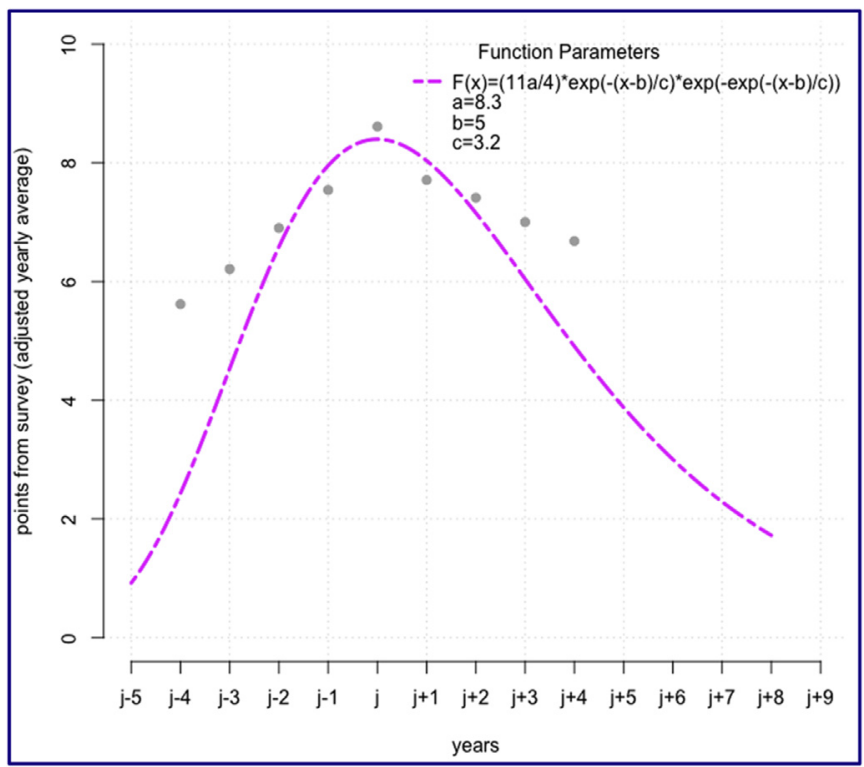

Figure A.2. Curve fitting from a Gumbel function.

Source: Authors

\section{References}

Ainslie, G. (1992). Picoeconomics. New York: Cambridge University Press.

Alexander, C. S., \& Becker, H. J. (1978). The use of vignettes in survey research. Public Opinion Quarterly, 42(1), 93-104.

Alwin, D. F. (2007). Margins of error: A study of reliability in survey measurement (Vol 547). John Wiley \& Sons.

Angelsen, A. (1991). Cost-Benefit analysis, discounting and the environmental Critique: Overloading of the discount Rate? Report 1991:5. Bergen: Department of Social Science and Development Chr. Michelsen Institute.

Arrow, K. J. (1970). Essays in the theory of risk bearing. Chicago: Markham.

Arrow, K. J., et al. (1995). Intertemporal equity, discounting and economic efficiency. In al., B.e. Climate change. Cambridge, UK: Cambridge University Press.

Arrow, K., et al. (2004). Are we consuming to much? The Journal of Economic Perspectives, $18(3), 147-172$.

Arrow, K. J., et al. (2013). Determining benefits and costs for future generations. Environmental Economics, 341, 349-350.

Arrow, K. J., et al. (2014). Should governments use a declining discount rate in project analysis? Review of Environmental Economics and Policy, 8(2), 145-163.

Arrow, K., \& Kurz, M. (1970). Public investment, the rate of return, and optimal fiscal policy. Washington, DC: Resources for the Future.

Barro, R. J. (1999). Ramsey meets Laibson in the neoclassical growth model. The Quarterly Journal of Economics, 114(4), 1125-1152.

Baumol, W. (1968). On the social rate of discount. The American Economic Review 58(4), 788-802.

Beck, M., \& Opp, K. D. (2001). Der faktorielle Survey und die Messung von Normen. Kölner Zeitschrift für Soziologie und Sozialpsychologie, 53(2), 283.

Biemer, P. P., Groves, R. M., Lyberg, L. E., Mathiowetz, N. A., \& Sudman, S. (2011).
Measurement errors in surveys (Vol. 173). John Wiley \& Sons.

Bradford, D. F. (1997). On the uses of benefit-cost reasoning in choosing policy towards global climate change. No. w5920. National Bureau of Economic Research.

Coleman, J. S., \& Fararo, T. J. (1992). Rational choice theory advocacy and critique. New York: Sage.

Dasgupta, P. (2007). The Stern Review's economics of climate change. National Institute Economic Review, 199, 4-7.

Eckstein, O. (1961). A survey of the theory of public expenditure criteria. Public finances, needs, sources and utilization. Princenton: Princenton University Press Nacional Bureau of Economic Research.

EPA. (2016). Discounting future benefits and costs. In U. S. E. P. Agency (Ed.), Guidelines for preparing economic analyses.

Evans, D., \& Sezer, H. (2004). Social discount rates for six major countries. Applied Economics Letters, 11, 557-560.

Feldstein, M. S. (1964). Time preference discount rate in cost benefit analysis. The Economic Journal, 74(294), 360-370.

Fernández-Baca. (2011). Actualilzación de la Tasa Social de Descuento Informe Final. Madrid: Dirección General de Programación Multianual del Sector Público del Ministerio de Economía y Finanzas de España.

Fisher, I. (1930). The theory of interest. New York: Macmillan Co.

Flyvbjerg, B. (2005). Measuring inaccuracy in travel demand forecasting: Methodological considerations regarding ramp up and sampling. Transportation Research Part A, 39, 522-530.

Frederick, S., Loewenstein, G., \& O'donoghue, T. (2002). Time discounting and time preference: A critical review. Journal of Economic Literature, 40(2), 351-401.

Freeman, M. C., \& Groom, B. (2014). positively gamma Discounting: Combining the opinions of experts on the social discount rate. The Economic Journal, 125(June), 1015-1024.

Freeman, M. C., Groom, B., Panapoulou, E., \& Pantelidis, T. (2015). Declining discount rates and the Fisher Effect: Inflated past, discounted future? Journal of Environmental Economics and Management, 73, 32-49.

Gatting, A., \& Hendricks, L. (2007). Judgmental discounting and environmental risk Perception: Dimensional similarities, domain differences, and implications for sustainability. Journal of Social Issues, 63(1), 21-39.

Gollier, C. (2011). Pricing the future: The economics of discounting and sustainable development. Princeton University Press.

Gollier, C., Koundouri, P., \& Pantelidis, T. (2008). Declining discount rates: Economic justifications and implications for long-run policy. Economic Policy, (23), $757-795$

Gollier, C., \& Zeckhauser, R. (2003). Collective investment decision making with heterogeneous time preferences. Gollier, Christian, and Richard Zeckhauser. Collective investment decision making with heterogeneous time preferences. No. w9629. National Bureau of Economic Research. w9629.

Groom, B., Hepburn, C., Koundouri, P., \& Pearce, D. (2005). Declining discount Rates: The long and the short of it. Environmental \& Resource Economics, 32, 445-493.

Groves, R. M., Mosher, W. D., Lepkowski, J. M., \& Kirgis, N. G. (2009). Planning and development of the continuous national survey of family growth. Vital and health statistics. Ser. 1 Programs and Collection Procedures, 48, 1-64.

von Hagen, H., Schuknecht, L., \& Wolswijk, W. (2011). Government bond risk premiums in the EU revisited: The impact of the financial crisis. European Journal of Political Economy, 27, 36-43.

Harris, C., \& Laibson, D. (2001). Dynamic choices of hyperbolic consumers. Econometrica, 69(4), 935-957.

Harrod, R. F. (1948). Towards a dynamic economics. London: Macmillan \& Co.

Henderson, N., \& Bateman, I. (1995). Empirical and public choice evidence for hyperbolic social discount rates and the implications for intergenerational discounting. Environmental and Resource Economics, 5(4), 413-423.

Herrnstein, R. J. (1961). Relative and absolute strength of response as a function of frequency of reinforcement. Journal of the Experimental Analysis of Behaviour, 4 267-272.

ISR. (2017). The panel study of income dynamics (PSID). A national study of socioeconomics and health over lifetimes and across generations. PSID main interview user Manual: Release 2017. Institute for Social Research, University of Michigan.

Karp, L., \& Lee, I. H. (2003). Time-consistent policies. Journal of Economic Theory, $112(2), 353-364$.

Kirby, K. N., \& Herrnstein, R. J. (1995). Preference reversals due to myopic discounting of delayed reward. Psychological Science, 6(2), 83-89.

Laibson, D. (1997). Golden eggs and hyperbolic discounting. The Quarterly Journal of 
Economics, 112(2), 443-478.

Laibson, D. (2003). Intertemporal decision-making. London: Nature Publishing Group.

Lee, J. Y., \& Ellingwood, B. R. (2015). Ethical discounting for civil infrastructure decisions extending over multiple generations. Structural Safety, 57, 43-52.

Leleur, S., Salling, K. B., \& Jensen, A. V. (2007). Documentation and validation of the TGB evaluation model in Greenland. Technical report prepared for the home Rule authorities in Greenland. Centre for Traffic and Transport, Technical University of Denmark.

Lewis, A. (2001). A focus group study of the motivations to invest: "Ethical/Green" and "ordindary" investors compared. Journal of Socio-Economics, 30, 331-341.

Lind, R. (1990). Reassessing the Government's discount rate policy in light of new theory and data in a world economy with a high degree of capital mobility. Journal of Environmental Economics and Management, 18, S2-S28.

Lind, R. C. (1995). Intergenerational equity, discounting, and the role of cost-benefit analysis in evaluating global climate policy. Energy Policy, 23(4-5), 379-389.

Little, I. M. D. (2002). A critique of welfare economics. OUP Oxford.

Loewenstein, G., \& Prelec, D. (1992). Anomalies in intertemporal choice: Evidence and an interpretation. Quartely Journal of Economics, 107, 573-597.

Lowe, J. (2008). Intergenerational wealth transfers and social Discounting: Supplementary green book guidance. London: HM Treasury.

Mazur, J. E. (1987). An adjustement procedure for studying delayed reinforcement. In $\mathrm{H} . \mathrm{N}$. J. Erlbaum (Ed.), The effects of delayed and intervening events on reinforcement value. Michael L. Commons, James E. Mazur, John A. Nevin and Howard Rachlin).

McLachlan, J., \& Gardner, J. (2004). A comparison of socially responsible and conventional investors. Journal of Business Ethics, 52(1), 11-25.

Meunier, D., Quinet, A., \& Quinet, E. (2013). Project appraisal and long term strategic vision. In In 41st European transport conference. Frankfurt: Elsevier, 2013.

Moellendorf, D. (2014). The moral Challenge of dangerous Climate Change: Values, poverty and policy. Cambridge University Press.

Moore, M., et al. (2004). Just give me a number!" practical values for the social discount rate. Journal of Policy Analysis and Management, 23(4), 789-812.

Newell, R. G., \& Pizer, W. A. (2003). Discounting the distant future: How much do uncertain rates increase valuations? Journal of Environmental Economics and
Management, 46(1), 52-71.

Olson, M., \& Bailey, M. (1981). Positive time preference. Journal of Political Economy, 89(1), 1-25.

Penyalver, D., \& Turró, M. (2017). Assessing the fairness of a project financing formula on successive generations. International Journal of Transport Economics, XLIV(1), 153-176. https://doi.org/10.19272/201706701008.

Pigou, A. C. (1920). Economics of welfare. London: Macmillan.

Pratt, J. W. (1964). Risk aversion in the small and in the large. Econometrica, $122-136$.

Ramsey, F. P. (1928). A mathematical theory of saving. Economic Journal, 38(152), $543-559$.

Rawls. (1972). A theory of justice. Clarendon Press.

Roumboutsos, A. B. (2010). Sustainability, social discount rates and the selection of project procurement method. International Atlantic Economic Society, 16, 165-174.

Samuelson, P. A. (1937). Some aspects of the pure theory of capital. The Quarterly Journal of Economics, 5(3), 469-496.

Saris, W. E., \& Gallhofer, I. N. (2014). Design, evaluation and analysis of questionnaries for survey research (2nd ed.). John Wiley \& Sons.

Scott, M. F. G. (1977). The test rate of discount and changes in base-level income in the United Kingdom. Economic Journal, 87, 219-241.

Scott, M. F. G. (1989). A new view of economic growth. Oxford: Clarendon Press.

Soman, D., et al. (2005). The psychology of intertemporal Discounting: Why are distant events valued differently from proximal ones? Marketing Letters, 16(3/4), $347-360$

Souto, G. (2003). El descuento social. Hacienda Pública Española/Revista de Economía Pública, 165(2).

Stiglitz, J. E. (2013). The rate of discount for benefit-cost analysis and the theory of the second best. Discounting for Time and Risk in Energy Policy, 3, 151.

Tinbergen, J. (1956). The optimal rate of saving. Economic Journal, 66, 603-609.

Treasury, H. M. (2003). The green book: Appraisal and evaluation in central government: Treasury guidance. Stationery Office.

Weitzman, M. L. (1998). Why the far-distant future should Be discounted at its lowest possible rate. Journal of Environmental Economics and Management, 36 201-208. 